\title{
Discursos do desenvolvimento: (in) visibilidade do social, modernidade e progresso em Imperatriz, MA
}

\author{
Development speeches: (in) visibility of social, modernity and progress in \\ Imperatriz, MA
}

\section{Discours de développement: (in) visibilité sociale, modernité et progrès à Imperatriz, MA}

\author{
Discursos del desarrollo: (in) visibilidad del social, modernidad y progreso en \\ Imperatriz, MA
}

\author{
Vanda Maria Leite Pantoja ${ }^{1}$ \\ Jesus Marmanillo Pereira ${ }^{1}$ \\ Recebido em 15/01/2018; revisado e aprovado em 25/03/2018; aceito em 06/06/2018 \\ DOI: http://dx.doi.org/ 10.20435/inter.v0i0.1812
}

\begin{abstract}
Resumo: Partindo da análise sobre os discursos produzidos a respeito da implementação da "moderna" multinacional Suzano Papel e Celulose, no município de Imperatriz, MA, a pesquisa discorre sobre os processos de invisibilização do "outro" nos discursos relacionados ao "desenvolvimento". Para tanto, nos valemos das contribuições de autores como Escobar (2005; 2007), Castro-Gómez (2005), Pinto e Mignolo (2015) e outros que nos auxiliam a pensar a tensão entre os conhecimentos tradicionais e a modernidade industrial, e refletir sobre como importantes atores sociais e instituições se posicionam a respeito dos projetos econômicos na Amazônia Maranhense.
\end{abstract}

Palavras-chave: saberes tradicionais; modernidade; desenvolvimento; progresso.

Abstract: Starting from the analysis of the discourses produced regarding the implementation of the "modern" multinational Suzano Papel e Celulose, in the municipality of Imperatriz, MA, the research discusses the processes of invisibilization of the "other" in the discursive processes related to the "development". In order to do so, we use the contributions of authors such as Escobar (2005; 2007), Castro-Gómez (2005), Pinto and Mignolo (2015) and others who help us think about the tension between traditional knowledge and industrial modernity, about how important social actors and institutions stand on economic projects in the Maranhão Amazon.

Keywords: traditional knowledge; modernity; development; progress.

Résumé: A partir de l'analyse des discours sur la mise en œuvre de la multinationale "moderne" Suzano Papel e Celulose, dans la municipalité d'Imperatriz, MA, la recherche discute des processus d'invisibilisation de "I'autre" dans les processus discursifs liés au "développement". Pour ce faire, nous utilisons les contributions d'auteurs comme Escobar (2005, 2007), Castro-Gómez (2005), Pinto et Mignolo (2015) et d'autres qui nous aident à réfléchir sur la tension entre savoir traditionnel et modernité industrielle, sur l'importance des acteurs sociaux et des institutions dans les projets économiques de l'Amazonie Maranhão.

Mots-clés: savoir traditionnel; modernité; développement; progress.

Resumen: A partir del análisis sobre los discursos producidos acerca de la implementación de la "moderna" multinacional Suzano Papel e Celulosa, en el municipio de Imperatriz, MA, la investigación discurre sobre los procesos de invisibilización del "otro" en los procesos discursivos relacionados al "desarrollo". Para ello, nos valemos de las contribuciones de autores como Escobar (2005, 2007), Castro-Gómez (2005), Pinto y Mignolo (2015) y otros que nos ayudan a pensar la tensión entre los conocimientos tradicionales y la modernidad industrial, y reflexionar sobre cómo importantes actores sociales e instituciones se posicionan respecto a los proyectos económicos en la Amazonia Maranhense.

Palabras clave: saberes tradicionales; la modernidad; el desarrollo; progreso.

\footnotetext{
${ }^{1}$ Universidade Federal do Maranhão (UFMA), Imperatriz, Maranhão, Brasil.
} 


\section{INTRODUÇÃO}

Sob uma retórica primeiramente salvacionista, depois civilizatória finalmente desenvolvimentista, povos e etnias posicionadas na periferia do novo centro do mundo, inclusive antigos impérios, em diferentes graus, têm sido desapropriados de suas terras; têm visto suas cosmologias, manifestações artísticas, ciências e tecnologias, formas de organização econômica e política serem reduzidas a superstições, mitos, folclores, tradições irracionais e idiossincrasias, quando não são totalmente suprimidas. Sob uma retórica emancipatória, povos e etnias periferizadas têm sido destituídas de sua subjetividade e dignidade. (PINTO; MIGNOLO, 2015, p. 9).

O presente artigo tem como objetivo problematizar a forma como o discurso sobre desenvolvimento tem sido construído na cidade de Imperatriz, MA, Nordeste do Brasil. Para tanto, partimos da análise sobre a produção de discursos que envolvem a chegada e implantação da "moderna" multinacional Suzano Papel e Celulose no município de Imperatriz, e a relação deles com as experiências das pessoas que vivem no contexto dos povoados da Estrada do Arroz, local onde se instalou a referida indústria. Por meio dessa situação, elencaremos os principais atores, classificações, instituições e suas inter-relações no trabalho social de construção de uma percepção de desenvolvimento, progresso e modernidade para a cidade de Imperatriz.

Para tanto, nos valemos das contribuições teórico-metodológicas de Escobar (2005; 2007), Castro-Gómez (2005), Pinto e Mignolo (2015), autores cuja perspectiva, conhecida como decolonial, explicita a forma como a tensão entre o "moderno" e o "tradicional" tem sido pensada nos processos de produções discursivas que enfatizam a viabilidade econômica e social de um modelo capitalcentrista (ESCOBAR, 2005) em detrimento da subalternização, colonização, invisibilização e finalmente anulação e morte do "outro". Para a presente pesquisa, isso significou um trabalho prático de mapeamento de relações, práticas e saberes que estavam vinculados a determinadas concepções de desenvolvimento, que eram produzidas por homens e mulheres inseridos diretamente nesse contexto de tensão.

Assim, a problematização sociológica e desnaturalização do termo "desenvolvimento" decorreu do próprio esforço de pensar e sistematizar a relação entre atores sociais e determinadas instituições que se encarregaram de oferecer forma e conteúdo para as narrativas sobre o desenvolvimento, na cidade de Imperatriz. Assim, mais que um fato, ou um dado que se autoexplica, a tomamos como construção social que emerge de um conjunto de relações, práticas e instituições que possuem todo um aparelhamento para a implementação de ideias e concepções de mundo.

Seguindo esse viés, nossa pesquisa de campo foi orientada para a obtenção de declarações públicas, entrevistas e documentações a qual nos possibilitasse compreender o processo de construção social do discurso de desenvolvimento em nível local, atentando para as diferentes versões que demarcam a tensão entre "tradicional" e "moderno" na narrativa do desenvolvimento. Nesse sentido, o trabalho de campo desenvolvido por meio de uma pesquisa documental, nos acervos do Curso de jornalismo da UFMA e na hemeroteca da Academia Imperatrizense de Letras. Nesse primeiro momento, tivemos acesso a 10 reportagens do jornal "O Progresso" que traziam informações históricas sobre a implementação da Suzano Papel e Celulose e a empresa Celulose do Maranhão (CELMAR) S/A, que se remetiam ao período entre a década de 1990 e o ano de 2014. Esse primeiro trabalho foi auxiliado pelo levantamento, realizado por Matos e Sousa (2016), que trazia 942 matérias, publicadas no Jornal "O Progresso", entre 2011 e 2017. 
Dessa primeira etapa, foi possível coletar declarações de representantes do poder executivo (municipal estadual e federal) e associações empresariais que explicavam a implementação da Suzano Papel Celulose como um símbolo do desenvolvimento.

Por outro lado, foram realizadas oito visitas de campo nas quais foi possível obter informações por meio de diálogos e oito entrevistas abertas com as diferentes lideranças da região. Para o presente artigo, foram selecionados os dados obtidos com os dois últimos presidentes do Fórum da Estrada do Arroz, que é uma associação que representa os povoados existentes na área de implementação do projeto industrial, desde 2011. Por questões de segurança, em alguns momentos do texto, os nomes próprios serão trocados por "Fórum da estrada do arroz". Tais diálogos, entrevistas e observações diretas sobre os povoados permitiram compreender o "outro" lado, a que muitos chamam de "tradicional".

As reflexões e interpretações resultantes de todo esse processo foram sistematizadas em três tópicos onde apresentaremos, 1) uma contextualização mais detalhadas sobre a cidade de Imperatriz em relação a uma narrativa desenvolvimentista, 2) os principais atores e discursos que garantiram uma (in)visibilidade pública sobre os impactos da implementação da monocultura do eucalipto em Imperatriz, e 3) as conclusões preliminares.

\section{LÓCUS DA CONSTRUÇÃO SOCIAL DA NARRATIVA DESENVOLVIMENTISTA NO “PORTAL DA AMAZÔNIA"}

Para quem busca acesso à região amazônica por meio da BR-010, ao chegar a Imperatriz, se deparará com um grande portal com os dizeres "Bem-vindo a Imperatriz, o Portal da Amazônia". Composto por dois pilares construídos com tijolinhos e contornados por uma estrutura de metal, na parte superior, que sustenta a placa da mensagem e uma grande tora de madeira. Tal monumento pode ser compreendido como uma espécie de altar de sacrifício, cujo ser sacrificado está exposto sobre a grande estrutura metálica que oferece suporte (literal e ideal) para uma metáfora sobre como é construída a concepção de desenvolvimento e a relação com a natureza no "Portal da Amazônia".

Seguindo a perspectiva crítica de Castro-Gómez (2005), podemos dizer que se trata de um sacrifício sustentado pelos princípios modernos de ciência, que eram defendidos por Francis Bacon. Isso porque, para o filósofo francês, a natureza era entendida como algo a ser domesticado, como um inimigo a ser vencido para que houvesse o domínio e centralidade do homem. Segundo o autor, a produção de conhecimento teria um papel fundamental nesse processo de domínio, pois "O papel da razão científico-técnica é precisamente acessar os segredos mais ocultos e remotos da natureza com o intuito de obrigá-la a obedecer nossos imperativos de controle" (CASTRO-GÓMEZ, 2005, p. 87).

Se a cidade de Imperatriz² está socialmente situada no "Bico do Papagaio", região conhecida pelos conflitos agrários, pelas relações de trabalho escravo e pelos assassinatos decorrentes de conflitos pela terra ${ }^{3}$, isso não ocorre de forma separada da lógica de domínio da natureza e

\footnotetext{
${ }^{2}$ Está, geograficamente, localizada no sudoeste do estado do Maranhão, em uma região com características fronteiriças que abarcam os estados do Pará e Tocantins.

${ }^{3}$ Um dos casos de assassinato que ganhou maior repercussão midiática foi a notícia sobre a execução do religioso e ativista pelos direitos a terra Josimo Morais Tavares, ocorrida no dia 10 de maio de 1986, no centro comercial de Imperatriz.
} 
relação com um "outro" classificado como tradicional. Antes de continuar com a argumentação, é importante destacar que se trata de um município que possui uma população estimada em 258.016 mil habitantes (IBGE, 2018) sendo considerado o segundo maior do estado, em termos populacionais e econômicos. Por meio da análise dos estudos de Franklin (2008) verificamos que a narrativa sobre o desenvolvimento da cidade foi fortemente influenciada pelo Plano de Metas proposto pelo presidente da república Juscelino Kubitschek (1956-1961), que, sob o slogan 50 anos de desenvolvimento em 5, construiu a BR-010, conhecida como Belém-Brasília.

A rodovia é responsável por ligar não só o Nordeste, mas a Amazônia Brasileira ao restante do Brasil, e colocá-la no circuito da economia global. Pode-se dizer que Imperatriz não adquiriu apenas notabilidade econômica com esse empreendimento federal, mas também que os sentidos e narrativas sobre a cidade também se alimentaram das palavras kubitschekianas, reproduzindose localmente por meio de uma série de declarações de políticos, empresários, associações e instituições diversas, inclusive aquelas dedicadas à produção de saberes.

Seguindo o viés analítico desenvolvido por Castro-Gómez (2005), podemos pensar que as primeiras classificações, e mais fortes classificações, em torno da cidade de Imperatriz eram alicerçadas em torno dos recursos naturais e acesso à Amazônia - algo que não está apartado do fato da história de a cidade ter sido atravessada por um ciclo de extração de madeira e da própria construção da BR-010. A forma como a área tem sido historicamente ocupada, e narrada, aponta um processo de "colonialidade do poder" que extrapola os dispositivos estatais e conecta-se ao sistema mundo capitalista, reforçando aspectos como o viés racionalista, os desencantamentos do mundo- materializados em práticas e nas declarações dos próprios atores do estado e intelectuais.

Nesse sentido, é possível problematizar as ações de Juscelino Kubitschek, na região, e (re) pensar os sentidos e vinculações presentes nas declarações e processos discursivos a respeito do desenvolvimento da cidade de Imperatriz, pois se trata, antes de tudo, de um discurso de domínio da natureza, vinculado a setores da economia industrial e que se vale da racionalidade como alicerce para inserir o local no global, ou seja, a região amazônica na economia capitalista mundial.

$\mathrm{Na}$ historiografia local, a cidade é mencionada em dois momentos: antes e depois da construção da BR-0104. Nesse sentido, qualquer narrativa que se faça sobre a cidade tem a construção da rodovia como momento fundante da modernidade e desenvolvimento na região, obliterando com isso um mundo de relações materiais e simbólicas que aconteciam quando o Rio Tocantins era tido como principal referência de comunicação. A cidade é "refém" de uma leitura sobre a economia local baseada em ciclos que necessitam que Imperatriz seja conectada ao Nordeste e ao resto do Brasil.

Assim, há toda uma bibliografia que explica que, até 1960, data da inauguração da BR-010, a economia do estado era entendida como "tradicional", pois estava centrada no extrativismo, principalmente do babaçu, e na agricultura de subsistência. Para a Federação das Indústrias do Estado do Maranhão (FIEMA) e intelectuais locais, a abertura da rodovia promoveu também o desenvolvimento de políticas de incentivos fiscais captadas via instituições como Superintendência para o Desenvolvimento da Amazônia (SUDAM) e Superintendência para o Desenvolvimento do Nordeste (SUDENE), inaugurando "novo ciclo de modernização" da economia local diversificando a base produtiva do Estado (FIEMA, 2009, p. 26).

\footnotetext{
${ }^{4}$ O trecho da BR que passa por Imperatriz começou a funcionar em 1960 e, em 1961, foi inaugurado pelo próprio Juscelino Kubitschek em visita à cidade (FRANKLIN, 2005, p. 86).
} 
Com o agronegócio no Sul e a exploração mineral no Oeste e Norte do Estado a partir da década de 1990, o Maranhão foi inserido em uma economia global, e também no início de uma jornada de desenvolvimento, segundo a perspectiva predominante na cidade de Imperatriz, MA. O que a historiografia local e os discursos "desenvolvimentistas" não consideram são as narrativas das formas econômicas existentes até então, antes desses projetos. Parece ocorrer um trabalho de invisibilização das particularidades materiais e simbólicas do Oeste Maranhense.

A nosso ver, esses silenciamentos e, às vezes, até "morte" dessa memória da cidade e da região podem ser explicados pelo fato de essas formas econômicas do passado não serem condizentes com a lógica de uma "economia moderna", sendo por isso suprimidas violentamente. Assim, considerando que as narrativas e processos discursivos do desenvolvimento local mobilizam atores do estado, da economia e da produção de conhecimento, é possível inferir que a "invenção do outro" tradicional é algo-socialmente e politicamente construído - que tende a ocultar processos identitários mais diretamente ligados à natureza. Sobre isso Castro-Gómez (2005, p. 88) explica:

Ao falar de "invenção" não nos referimos somente ao modo como um certo grupo de pessoas se representa mentalmente a outras, mas nos referimos aos dispositivos de saber/poder que servem de ponto de partida para a construção dessas representações. Mais que como o "ocultamento" de uma identidade cultural preexistente, o problema do "outro" deve ser teoricamente abordado da perspectiva do processo de produção material e simbólica no qual se viram envolvidas as sociedades ocidentais a partir do século XV.

Dialogando com esse viés, observamos que o discurso da modernidade inventa um "outro" a partir de uma percepção de mundo capitalcentrista e, portanto, considera as formas econômicas "tradicionais" dentro de um processo de incorporação que oculte ou subjugue aspectos da cultura que não dialoguem com os princípios da ciência moderna. Tal abordagem traria uma violência epistêmica contra povos que buscam economias de subsistência ou solidárias como, por exemplo, pequenos agricultores familiares, extrativistas, pescadores, enfim todos aqueles classificados como representantes de uma economia "atrasada" devem desaparecer, de acordo com essa lógica.

Sobre isso, Escobar (2007) observa a existência e reprodução de uma crença que propaga a modernização como única força capaz de dizimar relações arcaicas, não importando os custos sociais, culturais e políticos disso. Esse autor observa que o desejo de desenvolvimento ditado pelos chamados países do primeiro mundo está presente, por meio século, nas agendas políticas de países da Ásia, da África e da América Latina. No entanto tal sonho de desenvolver-se tem se tornado um verdadeiro pesadelo, pois, em vez de desenvolver, ele tem multiplicado "ao infinito" os problemas socioeconômicos desses continentes e das pessoas que nele habitam. Problemas ambientais, sociais e culturais têm sido o resultado de projetos de desenvolvimento que não consideram os saberes e projetos das populações locais e que, portanto, não são reconhecidos por essas populações.

Enquanto no campo discursivo das Ciências Sociais se trava um grande debate sobre as consequências nefastas da ideologia do desenvolvimento para os países "não desenvolvidos", nos países assim classificados se trava uma verdadeira empreitada que tem como ponto de chegada o "desenvolvimento". Tal fenômeno se dá tanto no campo discursivo quanto na efetivação de tais discursos, via políticas públicas com aval do governo e das elites locais.

Para Escobar (2007) o desenvolvimento é uma espécie de representação, de invenção, engendrada no período pós-segunda guerra que, desde então, tem orientado toda concepção 
de realidade de alguns países que se reconhecem como subdesenvolvidos. O autor se pergunta se é possível pensar outras formas de desenvolvimento no atual contexto de globalização? Com resposta positiva, ele atribui à efetividade disso projetos coletivos que envolvam a economia e o conhecimento como elementos fundantes de uma nova forma de ser livre, uma proposta posdesarrollo (ESCOBAR, 2007, p. 13).

\section{O CAPITALCENTRISMO ENCONTRA A COMUNIDADE: ALGUNS ATORES E DISCURSOS}

De modo geral, a região Nordeste do Brasil tem sido estigmatizada, representada e autoapresentada como pobre, e local que melhor exemplifica certa incapacidade em desenvolverse. Não são poucas as análises que realizam comparações entre os índices de pobreza no Estado do Maranhão com os países mais pobres da África do Sul ${ }^{5}$, reforçando uma imagem de subdesenvolvimento. Essa imagem sem esperanças não era diferente para a STCP Engenharia (2010), responsável pelo relatório de Impacto Ambiental da Suzano, que percebeu os municípios sul maranhense com uma baixa oferta de empregos, economia estagnada, agricultura familiar resistente e uma criminalidade crescente nos últimos anos.

Na cidade de Imperatriz, no estado do Maranhão, assim como no restante do Brasil, os discursos que propagam o desenvolvimento, também, não passaram por críticas que tivessem como base fundamental o "homem" local, em suas especificidades. Valorizaram-se muito mais as benesses quase proféticas dos empreendimentos econômicos, resultando em um processo de (re) produção material e simbólica homogeneizante que entende, idealmente, territórios como espaços vazios de significado, desconsiderando seus processos sociais de construção, em termos de formação de identidade, processos de territorialização e cultura.

Contrariando esse entendimento ideal, observamos que, por volta de 2009, os moradores dos onze povoados, localizados na Estrada do Arroz, no município de Imperatriz, começaram a ser assediados para vender suas terras. O assédio chegou pela pessoa de Francisco Leite, fazendeiro e morador local, dono de muitas terras. Ele perguntava se as pessoas queriam vender suas terras e trazia a notícia de que uma "grande fábrica" ia se instalar naquele local. A fala dele, segundo nosso informante, deixava claro que se tratava de "negócio grande", e muita expectativa foi gerada em torno disso. Além de Francisco muitos fazendeiros e agricultores locais venderam suas terras, nessa época, e se mudaram do local. Foi assim que os agricultores, pescadores, coletores e trabalhadores braçais que moram na Estrada souberam que a Suzano Papel e Celulose construiria uma fábrica nos espaços que eram suas roças e quintais até então.

A estrada do Arroz, MA-386, ganhou esse nome devido à grande produção de arroz que nela aconteceu entre as décadas 1950 e 1970, quando trabalhadores rurais fugindo de conflitos agrários chegaram àquela região, em busca de "terras livres", e se instalaram para fazer aquilo que sabiam fazer: lidar com a terra. As condições da estrada que dá acesso aos povoados ficaram, por mais de 40 anos, no mais completo abandono por parte dos governos, e foi asfaltada apenas no ano de 2016- quando passou a chamar-se Rodovia Padre Josimo em homenagem ao ativista religioso assassinato em 1986, por questões de conflito agrário.

No auge da produção de arroz, o transporte era feito por iniciativa dos próprios produtores locais em lombos de jumentos. Ao chegar à cidade de Imperatriz, ele era estocado nos vários

\footnotetext{
${ }^{5}$ Disponível em: http://g1.globo.com/ma/maranhao/noticia/2013/07/maranhao-tem-pior-renda-capitamedia-do-brasil-diz-nacoes-unidas.html. Acesso em: 5 jan. 2018.
} 
barracões, ainda existentes na Rua João Lisboa, onde eram beneficiados e exportados para vários estados do Brasil. Essa produção era tão importante para a dinâmica da região que, ainda hoje, quando se estuda a economia local, um dos recortes a que se faz referência é o "ciclo do arroz". Sobre aquele período, tem-se o seguinte relato:

Esse arroz que era produzido nos povoados era vendido por terceiros, tinham as pessoas que passavam, e levavam para a cidade. A fartura dessa época é descrita como sendo "as boas lembranças desse período" (Maria Lourdes Silva). ${ }^{6}$

Atualmente a Estrada do Arroz não possui produtividade de grande escala, constitui-se de pequenas lavouras onde famílias que plantam apenas para consumo próprio tentam sobreviver. A razão para o declínio da produção está relacionada ao processo de cercamento das terras que, sendo vendidas para grandes empresas e latifundiários vindos de outras paragens, foi sendo retirada do trabalhador rural e reorganizada em grandes fazendas. Esse processo, acontecido por volta da década de 1970, fez com que os trabalhadores que antes eram "donos" da terra, passassem à condição de funcionários dela a partir de arranjos, como a invenção do meeiro ou rendeiro. Essa passagem alterou sobremaneira a vida dessas famílias.

Quatro décadas após a chegada dos primeiros trabalhadores rurais, a região da estrada do arroz foi diretamente vinculada aos interesses da CELMAR S/A, que, segundo Santos (2009), expressava um projeto existente desde a década de 1970, no qual o governo federal almejava a plantação de eucalipto na região para atrair fábricas de papel ${ }^{7}$. É possível notar que, naquela década, ocorria uma grande mobilização de atores sociais e dos meios de comunicação para que a monocultura do eucalipto e a própria empresa fossem apresentados como os verdadeiros protagonistas do desenvolvimento econômico e social da região. Para se ter uma noção desse processo, basta verificar uma série de notícias, na imprensa escrita local, que traziam títulos ${ }^{8}$ como: "Celmar lança Programa GCQT", "Celmar presente na reunião da FIEMA". "Celmar faz ciclo de palestras informativas para a comunidade", "Celmar lança programa de educação ambiental", "Cientista defende o uso do eucalipto", "Seminário coloca em pauta projeto de reflorestamento da celmar", "Programa incentiva o plantio de hortas comunitárias" e outras que traziam atores e ações nos mais diversos campos, para demonstrar as "benesses" trazidas com a CELMAR.

Assim notamos que essa visibilidade midiática estava vinculada a uma diversidade de atores sociais, e sinaliza "estratégias de atuação para capitalizar seus discursos, idéias e a ações no espaço público de aparência e visibilidade social..." (BARROS, 2013, p. 322). Trazem assim, um desejo de eficácia política para um determinado ponto de vista que tende a ser defendido como de interesse público.

Em 2008, essa empresa foi comprada pela Suzano Papel e Celulose que deu seguimento à mesma lógica de operacionalização: com a continuidade da construção de uma imagem

\footnotetext{
${ }^{6}$ Entrevista em 19 de abril de 2016. Dona Maria Lourdes Silva, oriunda de Buriti Bravo, chegou no Povoado de Olho D’água dos Martins (na Estrada RO Arroz), em 1971, com dezoito anos de idade. Participou das Comunidades Eclesiais de Base, foi coordenadora do Fórum da Estrada do Arroz e vivenciou todo o processo de auge da produção de Arroz, da implementação da CELMAR e chegada de Suzano Papel e Celulose.

${ }^{7}$ Empresas não foram atraídas e toda a produção de eucalipto foi destinada à produção de carvão vegetal para abastecer as siderúrgicas localizadas no município de Açailândia. No final da década de 1990, a Celmar S/A Indústria de Celulose e Papel alterou seu nome apenas para Celmar; a partir de 2003, passou a chamar-se Fero Gusa S/A e, em 2008, foi comprada pela Suzano Papel e Celulose (SANTOS, 2009, p.137).

${ }^{8}$ Foram observadas nas edições do jornal "O Progresso" nas respectivas datas: 12/05/1996, 14/051996, 18/05/1996, 09/06/1996,12/06/1996, 23/11/1997,11/03/1998.
} 
pública de desenvolvimento econômico e social, e também na busca constante para incorporar o restante de terras que ainda estava sob posse do trabalhador, fazendeiro ou agricultor nesse grande projeto capitalcêntrico.

Assim, a inauguração da unidade industrial da Suzano no final de 2013 pode ser compreendida como o fechamento de um ciclo de expropriação que mobilizou uma serie de atores sociais e meios, e que inaugura uma nova fase na vida para trabalhadores rurais que ficaram desprovidos de terras. A situação atual pode ser sintetizada na fala de um morador local, que explica: "as comunidades não vão produzir porque é reserva. Onde não tem o eucalipto plantado ela (a empresa) diz que é reserva legal e não pode mexer" ${ }^{\prime \prime}$.

Se as notícias da década de 1990 mostravam todos os benefícios da Celmar para a cidade de Imperatriz, os diálogos com lideranças locais e a observação dos jornais dessa última década nos fizeram perceber que a chegada da Suzano significou, localmente, uma série de assédios para que camponeses vendessem suas terras para o fazendeiro Francisco Leite - que pode ser compreendido como uma espécie de mediador - e a continuidade do processo de construção de um discurso midiático de um "novo tempo" para o município, tempo de desenvolvimento, modernidade e, sobretudo, progresso.

O discurso proferido pelas autoridades políticas locais quanto à vinda da empresa para Imperatriz, assim como os enunciados de antes, durante e depois da inauguração desta, obedecem a um mesmo padrão de construção, isto é, caminham para a construção de uma (1) ideia de que somente há desenvolvimento a partir da matriz industrial, (2) de que o empreendimento é sinônimo de modernidade, (3) e revelam a incapacidade do Estado e seus agentes pensarem outra forma de desenvolvimento, visto que, em suas falas, fica claro que a cidade não re-existiria sem a empresa.

Assim, cabe definir em que sentido estamos empregando o termo discurso. De acordo com Pinto e Mignolo (2015), em ensaio onde refletem sobre o sentido da modernidade e de colonialidade, o discurso

Transcende a simples ideia de pronunciamento oral ou escrito para referir-se a todo um conjunto de percepções de si e do mundo que as diferentes comunidades de sujeitos elaboram interativamente. Inclui cosmologia, arte, filosofia, ciência, tecnologia, forma de organização econômica e política, direito. Em muitos contextos, é sinônimo de imaginário, narrativa e mesmo retórica, na acepção de discurso orientado à persuasão de ouvintes e leitores. (PINTO; MIGNOLO, 2015, p. 3).

Nesse sentido, a reconstituição das falas e leitura das reportagens nos aponta a mobilização de diferentes atores e saberes envolvidos na defesa da instalação dos projetos relacionados à monocultura do eucalipto. De modo mais claro, a fala do Secretário de Desenvolvimento do município de Imperatriz em 2012 evidencia uma perspectiva colonial, quando atribui a vinda da empresa como sinônimo de modernidade e progresso.

Se não fizermos isso [sediar a empresa], vamos continuar com a pecha de cidade interiorana. Portanto, esse projeto é de extrema importância para o município e Imperatriz agradece a Suzano por tê-la escolhido para implantar esses investimentos.

Assim, no âmbito governamental, temos uma narrativa salvacionista e triunfalista (PINTO; MIGNOLO, 2015) sobre a modernidade que, para atingi-la justifica toda sorte de expropriação

\footnotetext{
${ }^{9}$ Representante do Fórum da Estrada do Arroz, setembro 2017.
} 
e violência em nome do progresso e do desenvolvimento. De acordo com a perspectiva aqui trabalhada, a modernidade necessita de tais enunciados, aliás, ela somente se realiza enquanto discurso, enquanto entidade subjetiva já que não é algo natural, dado e objetivo, mas uma espécie de efeito do processo de interação via linguagem, entre sociedade e natureza. Por isso seu caráter discursivo.

No entanto à modernidade interessa ocultar seu caráter discursivo. É necessário que esta se apresente como 'realidade objetiva, "natural", necessária e "inevitável" (PINTO; MIGNOLO, 2015, p. 385), pois assim se exclui toda e qualquer possibilidade de contestação, de resistência ou busca de outros mundos.

Portanto os discursos dos agentes envolvidos no processo de atração e implantação da empresa Suzano para a cidade de Imperatriz, cumpriram a tarefa de produzir uma espécie de ambiente capaz de mostrar o caráter moderno do empreendimento, pois ser moderno significa ser bom, ser correto e, sobretudo, ser a única via capaz de levar ao desenvolvimento e consequente progresso. As falas das autoridades locais sobre o empreendimento estão em sintonia, elas destacam temas que, no imaginário local, remetem à temática da modernidade; e por que não falar da felicidade e do bem-estar da cidade?

Geração de emprego, por exemplo, é o tema recorrente nos enunciados de empresários e representantes do estado. Se por um lado, o Secretário de Estado do Trabalho e da Economia Solidária, José Antônio Helluy, afirmava "A Suzano é responsável por uma boa parte da oferta de emprego em nosso Estado" (O Progresso, 31/03/2012), em nível local, o resultado foi controverso, pois os empregos gerados apenas absorveram mão de obra durante os dois anos de implantação da estrutura física da empresa, quando essa fase terminou as pessoas foram demitidas. Atualmente poucos moradores trabalham na empresa, em funções de serviços gerais e na cozinha das empresas terceirizadas, funcionário da Suzano não há nos povoados, segundo dados do Fórum da Estrada do Arroz.

Essa mão de obra deslocada para a indústria no momento da feitura da estrutura física da empresa perdeu completamente o vínculo com a terra, visto que, quando foi dispensada do serviço operário, já não tinha terra para cultivar. Quando a Suzano chegou à cidade

[...] procurava dentro da comunidade quem queria trabalhar que tinha emprego "braçal", né. Aí então todo mundo entrou, quem quis trabalhar na Suzano trabalhou na época da construção, período. Ai, nessa época também teve uma redução também de produção também da agricultura familiar, porque todo mundo que tinha mesmo aquele pedacinho pequeno ou no vizinho deixou também, você podia pegar aqui de imperatriz a Petrolina que não se via um pé de feijão ou mandioca plantado na margem. Aí quando passou esse período da construção que aí dispensou todo mundo, esse período durou três anos, aí reduziu, dispensou todo mundo, ficou todo mundo desempregado [...] ai voltou novamente, se passa lá, você vai ver todo mundo com seu quintal tem tem um pezinho de mandioca, feijão plantado porque já sentiu a necessidade. Porque não tem mais condição de entrar na fábrica porque o serviço é mais especializado. ${ }^{10}$

A absorção seletiva e temporária dos trabalhadores rurais na construção da fabrica evidencia toda uma mudança de estilo de vida e organização que, como demonstra a fala do entrevistado, poderia ser percebida também na própria paisagem ao longo da estrada com ausência ou presença

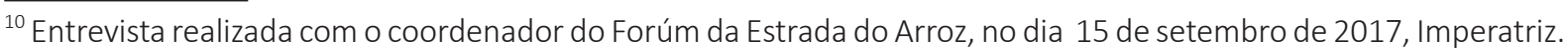
Por questão de segurança, omitimos o nome.
} 
de plantações de mandioca e feijão, sinalizando quase sempre a condição de empregabilidade do trabalhador rural: planta quando não está trabalhando na Suzano, ou seja, as condições e modos de trabalho apreendidas ao longo da vida e da sociabilidade primária já não são a única forma de caracterizar os trabalhadores rurais da estrada do arroz, durante e após a implementação da Suzano. Trata-se de uma mudança dos modos de trabalho que está diretamente vinculada às mudanças de percepções a respeito da relação com a terra: antes vista como elemento de ligação umbilical e estrutural para as famílias camponesas, atualmente classificada como "reserva" ou condição para o "desenvolvimento local" vida monocultura do eucalipto.

Em um diálogo ${ }^{11}$ realizado com Daniel Pereira Conceição Nascimento, que foi presidente de uma comunidade chamada Associação de Moradores e Produtores Rurais das comunidades Esperantina, São José da Matança e Açaizal (Ampema), e atualmente presidente do Forúm da Estrada do Arroz, é fácil observarmos o processo de desestruturação da unidade familiar camponesa por conta de "falta perspectivas de estudo para os filhos" e da migração de camponeses para outros estados; no caso do entrevistado, o próprios parentes migraram para o estado do Pará. Esse dado é importante quando pensamos a importância da questão associativa para a reprodução social no campo e o modo como a empregabilidade individual vai minando outras formas de relação com a natureza.

Meu pai veio de Barra do Corda, veio pra cá na época em que se chegava e demarcava a área e dizia assim esse pedaço aqui é meu. Muito tempo que ele mora lá povoado, ele era jovem e foi um dos primeiros. Eu mesmo já plantei, já colhi já fiz todo o serviço de arroz. Minha família já viveu disso. A área dele não era tão grande, mas pra gente que é do campo era uma área boa de tamanho são 81 hectares hoje. E como o povoado é pequeno e eram poucas pessoas que tinha área então ele além de fazer a roça no toco, na época né, ele também dava para a comunidade fazer também. Eram plantados arroz, feijão, milho e a gente mesmo fazia esse serviço. Como a familia dele é grande: são nove irmãos, sete mulheres e dois homens; então a gente mesmo fazia o serviço da roça. Ele só pagava pra brocar que era aquele mais pesado, mas a capina, a colheita, era tudo a gente que fazia a família toda. (Daniel Pereira Conceição Nascimento).

A relação entre diferentes formas de trabalho e com a terra pode ser sintetizada em perspectivas individualistas e associativas de trabalho. Traduzem diferentes concepções de mundo cujo impacto direto recai sobre as formas de organização social e reprodução social do capital, por um lado, e da família camponesa por outro. Atualmente o emprego oferecido pela empresa é mediado por empresas terceirizadas que, geralmente, têm contratado pessoas das comunidades "Matança", "Esperantina" e "Olho d'Água" por períodos de dois meses, a cada ano, para a realização de limpeza da estrada de acesso, do restaurante, jardim e demais atividades que exigem o exercício da força física. Ainda sobre a relação entre a implementação da Suzano e a geração de empregos, os povoados da estrada do arroz também permanecem invisibilizados nos discursos de representantes do poder executivo, que declaradamente retroalimentam o discurso capitalcentrista, como se pode observar no quadro a seguir:

\footnotetext{
${ }^{11}$ Contato realizado em setembro de 2017
} 
Quadro 1- Declarações que membros do poder executivo

\begin{tabular}{|c|c|c|}
\hline $\begin{array}{l}21 / 03 / 2014 \\
\text { o Progresso }\end{array}$ & $\begin{array}{l}\text { "Esses investimentos mudam a realidade da cidade, mudam de } \\
\text { patamar, pois é uma fábrica que dispõe de certificações internacionais, } \\
\text { que ajudam a modificar para melhor a cidade, a prestação de serviços } \\
\text { e incrementa a economia da segunda maior cidade do Estado do } \\
\text { Maranhão" }\end{array}$ & $\begin{array}{l}\text { Prefeito } \\
\text { Sebastião } \\
\text { Madeira }\end{array}$ \\
\hline $\begin{array}{l}21 / 03 / 2014 \\
\text { o Progresso }\end{array}$ & $\begin{array}{l}\text { Estamos inaugurando este empreendimento que significa a } \\
\text { transformação econômica de toda uma região, a concretização de um } \\
\text { antigo sonho desta população. Mais empregos foram gerados e novas } \\
\text { oportunidades de negócios estão sendo criadas. [...] É uma nova } \\
\text { realidade que está mudando a economia de todo o Maranhão". }\end{array}$ & $\begin{array}{l}\text { Governadora } \\
\text { Rosena Sarney }\end{array}$ \\
\hline $\begin{array}{l}21 / 03 / 2014 \\
\text { o Progresso }\end{array}$ & $\begin{array}{l}\text { "Esta é uma realização com esforço dos empresários, do governo e dos } \\
\text { maranhenses. É um empreendimento com investimento volumoso de } \\
\text { recursos para sua criação e manutenção, e ao mesmo tempo é intensivo, } \\
\text { porque abriu frentes de trabalho e empregou milhares de pessoas. } \\
\text { Significa um enorme benefício para a economia do Maranhão e do } \\
\text { Brasil. Parabenizo a todos por esta iniciativa". }\end{array}$ & $\begin{array}{l}\text { Presidenta } \\
\text { Dilma Rousseff }\end{array}$ \\
\hline
\end{tabular}

Fonte: Elaboração dos autores (2017).

As declarações reforçam uma narrativa da realidade social que é condicionada ao avanço da economia, explicitam a geração de empregos, consolidam o protagonismo dos empresários e dos políticos no processo de implementação da fábrica, deixando de fora os impactados diretos com o "empreendimento", as populações locais que viviam na região da estrada do arroz muito antes de qualquer plano econômico para a região.

Tomando os estudos de Escobar (2005) como referência, podemos dizer que, ao tomar toda a região como "espaço", desconsiderando a existência de territorializações construídas por meio da interação com dos povoados, as declarações públicas analisadas na imprensa local invisibilizam os primeiros atores sociais da região e reforçam a narrativa capitalcêntrica. Nesse sentido, as falas coletadas com a população local oferecem outras possibilidades de se pensar o desenvolvimento e considerar a diversidade de culturas e histórias enraizadas naquelas terras.

Em poucos exemplos disso, podemos citar a própria história de Daniel Pereira Conceição Nascimento, que nasceu na região e é filho de lavrador e de quebradeira de Coco Babaçu, que chegaram por volta da década de 1950 nas mediações da estrada do Arroz. Lá também observamos Maria Querubina, conhecida como Querubina, é uma das principais lideranças do Movimento Interestadual das Quebradeiras de Coco (MIQCB), e também da Vila Conceição, que foi resultado de ocupação da fazenda Itacira, ocorrida em julho de 1987, e representa uma importante referência de reforma agrária no interior do estado (COSTA, 2013).

Essas declarações extraídas de um conjunto de 20 recortes, pertencentes a um conjunto mais amplo de notícias ${ }^{12}$, apontam que a associação discursiva que mescla desenvolvimento, modernidade e a instalação da empresa, em Imperatriz, foi consolidada sob a égide do poder público em diferentes espaços (câmara de vereadores, Palácio do Comércio e até mesmo no

\footnotetext{
${ }^{12}$ Foi considerado o levantamento de 942 matérias, publicadas entre 2011 e 2017, que auxiliaram o estudo "O Papel do Progresso: uma Análise da Presença da Fábrica Suzano de Papel e Celulose em O Progresso" de Marcos Fábio Belo Matos e Letícia Holanda de Sousa (2016), mais levantamentos feitos no próprio site do referido veiculo de comunicação.
} 
canteiro de obras da empresa) para defender e incentivar a matriz industrial como sinônimo de desenvolvimento. Os moradores da Estrada do Arroz sequer eram 'citados nas notícias analisadas. Quando se observa esse conjunto de atores de diferentes instituições que se manifestam em diversos locais, tem-se em mente a situação descrita por Escobar (2005) quando nota que o desenvolvimento resulta de um conjunto de relações entre elementos institucionais e práticas que dão base à ideologia capitalcentrista, que não admite outras possibilidades de desenvolvimento.

Tal ideologia se traduz em um raciocínio de desenvolvimento (sem reconhecimento) que é bastante explícito não só nas declarações dos governantes ou na imprensa, que maciçamente visibilizava as benesses do investimento, mas reproduz também a lógica da Federação das Indústrias do estado do Maranhão, que entende que a solução para se alcançar o "desenvolvimento" é "reduzir a dependência da economia de um pequeno conjunto de produtos e setores, incluindo a agregação de valor dos produtos maranhenses, deve se perseguir a diversificação da estrutura produtiva, com a industrialização da economia" (FIEMA, 2009, p. 52).

Enfim, é importante salientar que se trata de uma guerra de percepções sobre o desenvolvimento, sobre a relação com a natureza que se sustenta também em uma disputa pela legitimidade dos saberes, pois a FIEMA, os chefes do executivo e o setor empresarial, no trabalho de convencimento a respeito das benesses da monocultura do eucalipto, lançaram mão de uma série de especialistas ${ }^{13}$ como: engenheiros agrônomos, e silvicultores, médicos, químicos, biólogos, pedagogos, assistentes sociais, geógrafos, fotógrafos e jornalistas que buscavam demonstrar, cada um em sua especialidade, os benefícios da empresa para o desenvolvimento econômico e social da região.

As páginas praticamente invisibilizam os líderes locais com os quais tivemos contato e outras organizações como a Caritas, o Centro de Estudos do Trabalhador Rural (Centru), os sindicatos dos trabalhadores rurais, Movimentos de Educação de Base (MEBs) e outros ligados aos camponeses, quebradeiras de coco babaçu e outros. Diferentemente da grande atenção dada aos especialistas recrutados para defender as empresas ligadas ao eucalipto, a aparição dos debates e reflexões sociais sobre os projetos econômicos para a região aparecem timidamente e vinculados a essas organizações associativas.

Se, de um lado, lideranças como Dona Querubina ou Daniel Pereira Conceição Nascimento, nativos com anos de experiência e relação com a terra, explicam que alguns moradores relatam que a terra já não é tão boa quanto antigamente e que alguns córregos, cujas nascentes ficaram restritas à área da empresa, mudaram de cor; o cidadão imperatrizense de década de 1990 poderia pegar seu Jornal Progresso de uma quarta-feira, 13 de junho de 1996, e ler a explicação do engenheiro agrônomo Paulo Tarso Alvim, que defendia cientificamente o uso do eucalipto e afirmava ser possível conciliar plantações de eucalipto com outras culturas sem danificar o solo. O interessante é que a reportagem ainda endossa e enfatiza que se trata da explicação de um PHD em fisiologia vegetal na Universidade de Cornell no EUA.

Em relação à Suzano Papel Celulose, o posicionamento veio do Relatório de Impacto Ambiental (RIMA) que somou o trabalho de uma equipe de 19 especialistas das áreas de Agronomia, Engenharia Florestal, Biologia, Geografia, Meteorologia, Engenharia Cartográfica,

\footnotetext{
${ }^{13}$ As profissões e atores envolvidos podem ser verificados detalhadamente nas edições do jornal "O Progresso" nas seguintes datas: 12/05/1996, 14/051996, 18/05/1996, 09/06/1996, 12/06/1996, 23/11/1997, 11/03/1998.
} 
Advocacia, Geologia, mais uma equipe de apoio com 17 membros que eram técnicos, estudantes e profissionais. O relatório elaborado em 2010 aponta que há um consenso, do ponto de vista econômico, sobre a importância do setor privado como "bom empregador e fomentador de progresso". Afirma que o próprio poder público apoia o projeto da Suzano, pois acreditam que

A inserção do plantio de eucalipto nessas regiões encontra um campo fértil para apoio políticos e dos munícipes, pois muitos crêem que a chegada do empreendimento da Suzano aumentará a oferta de emprego e propiciará um maior desenvolvimento econômico e social das cidades. (STCP ENGENHARIA, 2010, p. 4.30).

Ironicamente, os técnicos e pesquisadores contratados pela própria empresa, citam não apenas o entusiasmo dos administradores públicos, mas explicam também que as populações rurais dos municípios maiores, particularmente Estreito, Imperatriz, Campestre do Maranhão e Buritirana, apresentam grande preocupação com os impactos negativos decorrentes dos grandes empreendimentos. Em uma escala mais detalhada, segue explicando:

De um modo geral, os moradores das áreas próximas aos projetos, que sofrem a falta de recursos financeiros e de incentivos, são unânimes em dizer que os grandes empreendimentos geram riqueza para poucos e a destruição e pobreza para muitos. (STCP ENGENHARIA, 2010, p. 4.31).

Enfim, a própria empresa afirma, no relatório, que a resistência e o questionamento parecem vir, unicamente, dos próprios povoados das áreas afetadas, não havendo qualquer ponderação ou resistência por parte dos governos. Temos um desenho de uma relação complexa entre a Suzano e as comunidades tradicionais e a opinião pública em geral, por meio de uma série de mediadores, que podem ser pensados nos líderes dos governos, no empresariado local e no conjunto de especialistas recrutados para estruturar e reforçar a fábula do desenvolvimento (sem reconhecimento).

\section{CONSIDERAÇÕES FINAIS}

Pensada como a cidade do progresso, a cidade de Imperatriz reproduz em sua história, na prática de seus principais atores políticos, uma ideia de desenvolvimento que pode ser pensada como "fora do lugar" e ancorada em um conjunto de classificações que existem em oposição ao "tradicional", "extrativista" e "arcaico". A rota urbanização-industrialização e desenvolvimento tem sido propagada como única possibilidade para se pensar a produção e reprodução econômica do município.

Quando realizamos uma simples problematização a respeito da territorialização da Suzano na cidade, é possível visibilizar um conjunto de atores e organizações cujo poder de classificar serve como a mola propulsora da narrativa do desenvolvimento. Tem-se a articulação de políticos das mais diferentes esferas, dos meios de comunicação, e mediadores responsáveis por aglutinar as terras para a produção de eucalipto, e lideranças locais que são incorporadas na própria lógica dessa narrativa do desenvolvimento. Trata-se de um esquema mais amplo, que se inicia com a classificação do próprio estado, que é tido como pobre e passível de ser "salvo" por um setor empresarial compreendido como investidor. Trata-se de uma narrativa heroica na qual os protagonistas são sempre de fora do lugar: um presidente que fala em "integrar" um local com o resto do país ou uma empresa multinacional compreendida como o símbolo verdadeiro do desenvolvimento e dos "novos tempos". 
O discurso do desenvolvimento na cidade de Imperatriz só pode ser compreendido quando consideramos as diferentes classificações e atores que expressam as diferentes concepções de mundo a respeito do desenvolvimento local. Embora tenha ocorrido "a grande promessa", o que se efetivou de fato foi uma forte articulação política e discursiva que imobilizou, quase totalmente, um sistema de vida baseado na agricultura familiar. Os moradores da Estrada do Arroz se ressentem de não conseguir que a empresa fomente a agricultura familiar no local; esta era uma das esperanças das pessoas quando souberam que uma "grande empresa" se instalaria na região e traria progresso e desenvolvimento, afinal, segundo a lógica local, o que mais pode significar desenvolvimento e progresso para agricultores, senão o fomento para as práticas da agricultura familiar?

Atualmente a estrada passa por um processo de metamorfose que transforma agricultor familiar em operário da fábrica e, depois, em desempregado. Uma história complexa envolta por uma máquina de produzir discursos altamente eficientes que, muitas vezes, é capaz de obliterar o mundo vivido em prol da ficção do desenvolvimento.

\section{REFERÊNCIAS}

BARROS, Antonio Teixeira de. A visibilidade ambiental em perspectiva sociológica: estudo comparado Brasil-Portugal. Sociologias, Porto Alegre, RS, v. 15, n. 33, p. 318-45, ago. 2013.

CASTRO-GOMEZ, Santiago. Ciências Sociais, violência epistêmica e o problema da "invenção do outro". In: LANDER, Edgardo (Org.). A colonialidade do saber: eurocentrismo e ciências sociais. Perspectivas latino-americanas. Ciudad Autónoma de Buenos Aires, Argentina: Clacso, set. 2005. p. 133-68. (Col. SurSur).

COSTA, José Luís da Silva. Terra de bravura e utopia: Vila Conceição I e II, o primeiro assentamento da região tocantina. 1. ed. Imperatriz, MA: Ética, 2013. v. 1. 148p

ESCOBAR, Arturo. La invención del Tercer Mundo. Cosntrucción y deconstrucción del dessarollo. Caracas, Venezuela: El Perro y Larana, 2007.

ESCOBAR, Arturo. O lugar da natureza e a natureza do lugar: globalização ou pós-desenvolvimento? In: LANDER, Edgardo (Org.). A colonialidade do saber: eurocentrismo e ciências sociais. Perspectivas latinoamericanas. Ciudad Autónoma de Buenos Aires, Argentina: Clacso, set. 2005. p. 133-68. (Col. SurSur)

FIEMA. Plano estratégico de desenvolvimento industrial do Maranhão. 2009. Disponível em: https://www. fiema.org.br/uploads/revista/6330/MxlkzuXMhbpFZihAGiO4yBtZ6KdYCGpn.pdf

FRANKLIN, Adalberto. Apontamentos e fontes para a História Econômica de Imperatriz. Imperatriz, MA: Ética, 2008.

FRANKLIN, Adalberto. Breve história de Imperatriz. Imperatriz, MA: Ética, 2005.

IBGE. População-Imperatriz, MA. 2018. Disponível em: https://cidades.ibge.gov.br/brasil/ma/imperatriz/ panorama

MATOS, Marcos Fabio Belo; SOUSA, Letícia Holanda de. O papel do progresso: uma análise da presença da fábrica Suzano de Papel e Celulose em O Progresso. 2016. Disponível em: http://docplayer.com. br/48638958-O-papel-do-progresso-uma-analise-da-presenca-da-fabrica-suzano-de-papel-e-celuloseem-o-progresso-1.html 
PINTO, Júlio Roberto de Souza; MIGNOLO, Walter. A modernidade é de fato universal? Reemergência, desocidentalizaçãoe opção decolonial. Civitas, Porto Alegre, RS, v. 15, n. 3, p. 381-402, jul./set. 2015.

SANTOS, Raimundo Lima dos. O projeto Grande Carajás e seus reflexos para as quebradeiras de coco de imperatriz - MA. 2009. Dissertação (Mestrado em História) - Universidade Federal de Goiás (UFG), Goiânia, 2009.

STCP ENGENHARIA DE PROJETOS. Relatório de Impacto Ambiental - Rima da área de implantação do projeto florestal da Suzano, na região de Porto Franco, estado do Maranhão. Curitiba, jan. 2010.

\section{Sobre os autores:}

Vanda Maria Leite Pantoja: Doutora e Mestre em Antropologia, Universidade Federal do Pará (UFPA), Bacharel e Licenciada em Geografia (UFPA). Professora adjunta da Universidade Federal do Maranhão (UFMA), Campus II. Líder do Núcleo de Pesquisa sobre Religião e Religiosidade da UFMA. Membro do grupo de pesquisa \&quot;Simbolismo, Religião e Saúde\&quot; do Departamento de Antropologia da Universidade Federal do Pará e Núcleo de Estudos Sociedade e Cultura na Amazônia Oriental (NESCAO). Atua nos seguintes temas de pesquisa: Catolicismo Popular, Pentecostalismo, Território e Desenvolvimento. E-mail: vanpantoja@gmail.com

Jesus Marmanillo Pereira: Doutor em Sociologia pelo Programa de Pós-graduação em Sociologia da Universidade Federal da Paraíba (PPGS-UFPB). Mestre em Ciências Sociais pela Universidade Federal do Maranhão (PPGCSOC-UFMA). Graduado (Bacharelado e Licenciatura) em Ciências Sociais e História pela mesma instituição. Possui também licenciatura em Geografia pela Universidade Estadual do Maranhão. Professor assistente da Universidade Federal do Maranhão (CCSST-Imperatriz), coordenador do Laboratório de Estudos e Pesquisa sobre Cidades e imagens (LAEPCI), membro do Laboratório de Estudos e Pesquisa em Políticas Públicas e Trabalho (LAEPT-UFPB) e do Grupo de Pesquisa em Antropologia Visual e da Imagem (VISAGEM-UFPA). Tem experiência na área de Antropologia Visual, História Social, Sociologia Política, Sociologia Urbana, atuando principalmente em temas relacionados a etnografias visuais, movimentos sociais e identidades coletivas, populações estigmatizadas na cidade e violência urbana. E-mail: jesusmarmanillo@hotmail.com 
